\title{
Factors affecting housing-seeking difficulty for battered women: an investigation of racial discrimination and attitudes held by landlords
}

\author{
Monica Ghabrial and Paula Barata* \\ *This manuscript was prepared under the supervision of Professor Barata, \\ Department of Psychology, College of Social and Applied Human Sciences, \\ University of Guelph, Guelph, Ontario, Canada
}

\begin{abstract}
Research has revealed that battered women often face difficulty when searching for long-term housing, which in turn, often leads to homelessness. Because housing discrimination has also been found in studies regarding racial prejudice, this research was designed to investigate a potential interaction between the effects of racial discrimination and discrimination against battered women in housing-seeking. In a telephone audit study, two confederates - one with a Canadian accent and one with a Caribbean accent - called 180 landlords who had advertised for a one-bedroom apartment, and disclosed one of three living conditions (i.e., a shelter for battered women, a friend's house, no disclosure), while asking if the apartment was still available. The apartment was 4.50 times less likely to be reported as available when the confederate called claiming to be staying at a shelter than when she did not disclose a living situation. The accent of the confederate had no main effect and there was no interaction between accent and current living condition. A separate sample of 41 landlords was surveyed and asked for general views on battered women, risks that deterred them from wanting to rent to battered women, and sources for the information on which these concerns were based. The results of the studies suggest that landlords feel justified in discriminating against battered women; however, they are aware that racial discrimination is illegal and thus avoid this behaviour. Factors that could potentially make landlords more comfortable about renting to battered women are discussed.
\end{abstract}

Cana anadian women are four times more likely than men to be threatened or harmed by someone close to them, twice as likely to be threatened or attacked with a weapon, five times more likely to report being choked, and much more likely to fear for their lives and their children's lives as a result of domestic violence [1]. Often times, women who have sought out protection orders or support from the civil justice system in evicting their abusers have been denied [2]. When this occurs, these women are forced to choose between staying in the abusive environment and leaving their home with potentially nowhere to turn. Through interviewing a group of women who had experienced spousal abuse, Sev'er found that more than half of those questioned reported that their reason for staying in the relationship for as long as they did was the concern that they would not find a decent place to live [3]. When women do leave, threats, stalking, and physical violence are reported to often increase after the separation - further emphasizing the need for community support and safe housing [4]. At this point, an abused woman must often take temporary refuge in a shelter or emergency centre. The duration of the stay can vary from a few days to a few years, but eventually she is forced to either find a long-term residence or return to the home of the abuser. Research has revealed that women in this situation often experience difficulty when searching for housing. It has been reported that women who flee, but disclose a history of domestic abuse to potential landlords while seeking longterm housing have an increased risk of repeated stays at a shelter, which in turn makes them more prone to eventual homelessness [5, 6]. There are also instances of landlords showing discrimination against battered women, displayed in a study by Baker, Cook, and Norris, in which 27 percent of interviewed battered women reported being threatened with eviction post-separation [7]. These findings display an urgent need for the availability of safe and affordable housing, lest a woman stay in an abusive relationship for lack of alternatives.

Audit studies involve presenting subjects with two nearly identical confederates who differ in one distinct way to observe if and how the subject will respond to each person differently. This method helps to reveal prejudiced behaviour by avoiding the influence of social desirability in ways that surveys cannot. Barata and Stewart directly investigated the willingness of landlords to rent to battered women by having 
auditors contact landlords who had placed advertisements for a one-bedroom apartment in Toronto. The experiment revealed that auditors who claimed to be staying at a shelter for battered women were 10 times less likely to be told an apartment was available than those who did not reveal information about their current living situation. A separate sample of landlords who had advertised for a one-bedroom apartment were called and surveyed to inquire after concerns regarding renting to a battered woman and their willingness to accept a battered woman as a tenant. When asked if they felt that renting to a battered woman would be a risk, 20 percent agreed. The most common risk listed was that the abuser may come to the building looking for her; however, these participants did not explain the specific outcomes they were worried may result. Furthermore, 23 percent stated that they would not rent to a battered woman, indicating that a third of these landlords felt justified in not renting to battered women [8]. These findings help explain that while about 50 percent of battered women surveyed by Baker, Cook, and Norris left their homes, 38 percent became homeless after separating from their abusive partners [7].

Studies of renting and sales situations regarding racial discrimination show similar biases. The Housing New Canadians Project was designed to investigate the difficulties faced by new immigrants in Toronto. In a comparison of perceived discrimination, Somali and Jamaican immigrants reported experiencing more housing discrimination than Poles, and Somali women reported experiencing the greatest amount of housing discrimination of all groups [9]. In an audit study, Yinger found that Black housing-seekers were told that units were unavailable on 30 percent more occasions than were White housing-seekers [10]. Landlords in Toronto showed similar behaviour in an audit study involving single South Asian males and Black single mothers [11].

Considering the discriminatory behaviour shown in response to battered women and new immigrants, it may come as no surprise that ethnic-identified battered women must often face great barriers. Although reports of intimate partner violence against White women, Black women, Asian women, and Hispanic women are similar [12, 13], research has shown that non-White battered women are much less likely to take refuge in a shelter than their White counterparts $[14,15]$. To investigate this discrepancy, Donnelly, Cook, Ausdale, and Foley interviewed employees and executive directors associated with multiple shelters. Interviewees displayed a tendency to make implicit assumptions about the latter, as well as discussing distinct observed differences between the groups - despite the claim of maintaining a "colour-blind" environment. Black battered women were labelled as more aggressive and more likely to use drugs than White battered women. Interviewees also stated that fewer Latinas were present in a given shelter because most were illegal immigrants. One participant even admitted to changing the location of her shelter to make it less accessible to Black women and more so to White women - revealing a complete disregard for antidiscrimination laws and a failure to acknowledge the needs of women of colour [16]. Shelters are intended to be a safe and accepting environment for battered women to take refuge - making these findings particularly disconcerting. If women of colour who suffer from domestic abuse are not ensured an impartial safe-place, it is more likely that they will either stay with the abuser or become homeless. Furthermore, if individuals who work in shelters for battered women do not provide their services free of prejudice, it is likely that landlords who are not trained to help women in this situation will also respond negatively to these individuals, and possibly with the same stereotypes in mind.

The current study was designed to investigate a potential interaction between the effects of racial discrimination and discrimination against battered women in housing-seeking, and to gain a further understanding of the bases for prejudice towards battered women. The experimental phase took the form of a telephone audit study similar to that used by Barata and Stewart, to investigate the difficulties faced by ethnic-identified battered women when searching for long-term housing [8]. The calls to landlords were made by either a female with a Canadian accent or a female with a Caribbean accent. In each call, the confederate revealed that she was currently living at either a) a shelter for battered women, b) a friend's house, or c) she did not state a current living situation. The friend's house condition was used to ensure that revealing a current living condition or not being perceived as financially self-sufficient is not a significant influence on the landlord's response and that any notable difference in responses is provoked only by the fact that the caller is a battered woman. As the three Canadian cities that were called each have a relatively small population, it is possible that many of the landlords within each city are acquainted with one another. To eliminate the possibility that a landlord would discuss the study to any other local landlords after being called by the confederate, no debrief was provided. In the Barata and Stewart audit study, only two landlords appeared somewhat alarmed upon learning the true nature of the call - but were satisfied when the caller offered to provide a letter explaining the study in greater detail; thus, when designing the current study, it was presumed that no risk would result from the use of deception.

The survey phase of this study was conducted with a separate sample of landlords, inquiring after attitudes and preconceived ideas about battered women, as well as willingness to rent to a battered woman. At the end of the survey, the interviewer asked landlords to not disclose the content of the call to anyone to avoid the possibility that any landlords selected for the audit study would have heard of the research beforehand. The survey was designed to achieve a greater understanding of the stigma towards battered women and how these ideas develop, with hopes to eventually educate the public, eliminate any harmful stereotypes, and 
subsequently bring ease of finding a long-term home to battered women. It was hypothesized that apartments called in the audit study would be reported as available less often for shelter conditions than in the friend's house and control conditions. An interaction was predicted to occur when callers who revealed that they were living in a shelter for battered women were also identified as ethnic by landlords resulting in fewer reported available apartments in this condition than in all others.

\section{METHODS}

\section{Audit Study}

Participants. Data from 186 landlords who had advertised for a one-bedroom apartment in one of the three selected medium-sized Canadian cities was collected. Two of these phone-calls were removed from the data because the confederate strayed from the script. Another four of the calls were removed because the individuals reached were renting agents or administrative assistants for large retail companies. Thus, data from 180 landlords (85 females, 95 males) was used in analysis. The Canadian confederate called 90 of these participants, and they were distributed evenly between the three current living conditions (30 landlords called under each condition). The 90 landlords called by the Caribbean confederate were distributed evenly among the three living conditions as well. Phone numbers were collected through the housing classifieds of the local newspapers, Kijiji.ca, 247apartments.com, Skylineonline.ca, Apartmentcorner.ca, and Gscrentals.com. On the first day of calls, all available advertised prices were averaged. Based on this average, a price bracket for the callers was calculated, by adding 166.28 dollars (2 standard deviations) below the average, and 166.28 dollars above (See Barata \& Stewart, 2010). Thus, only landlords advertising apartments with prices ranging from $\$ 629.18$ to $\$ 961.74$ were contacted.

Originally, 247 telephone numbers were selected and called for the study. Of these, 34 led to a company recording which stated that the call may be recorded. These calls were not completed. 27 of the numbers led to a machine at each attempt. The remaining 186 numbers were those discussed above.

Procedure. This study had a 2 (Canadian, Caribbean) $\mathrm{x}$ 3 (shelter, friend's house, control) design. Two female confederates, who were approximately twenty years old - one with a Caribbean accent and one with a Canadian accent called landlords to inquire after availability of the advertised one-bedroom apartment. Each call contained one of three conditions: a) currently living in a shelter, b) currently living at a friend's house, and c) no mention of current living situation.

In the shelter condition, the confederate began the call with the following line: "Hi, I'm calling about the onebedroom apartment. And actually, I'm living in a shelter for battered women right now, so I'd be interesting in moving whenever possible. Is the apartment still available?" In the friend's house condition, the caller stated that she is currently living at a friend's house, and in the final control condition, the caller did not provide information regarding her current living situation ("Hi, I'm calling about the one-bedroom apartment. And actually, I'd be interested in moving whenever it's possible. Is the apartment still available?"). The caller took note of the landlord's response and the alleged availability of the apartment, then thanked the landlord for his or her time, and concluded the phone call.

Before calls were made each day, R 2.10.1® was used to randomly assign all phone numbers in the database that had not yet been reached to one of the six different conditions. Throughout the study, a temporary record of telephone numbers was kept to ensure that a single landlord was not contacted more than once. To ensure confidentiality and that reponses could not be traced back to telephone numbers, data was stored separately from the phone numbers and was not associated with them in any way. All participants were assigned a number and records were only accessible by experimenters. Up to four attempts were made to call each number and when the landlord did not answer the phone by the fourth attempt, the phone number was flagged as "No Response (NR)” in the database.

As experimenters called claiming to be a housingseeker interested in renting the apartment, landlords were not in a position to give consent to participate. At times, landlords asked the confederate if she was a student, if she was moving in by herself, and if she was employed. To these questions, confederates were instructed to respond with no, yes, and yes, respectively. When asked what their current working position was, confederates responded by either saying that they were waitressing, or that they cleaned houses for a living. Experimenters were instructed to take note of comments and questions made by landlords on the script used. Six landlords asked the callers if and where they were currently employed across conditions, and five landlords asked the caller if she planned to move in by herself. Additionally, six landlords in the Caribbean accent scenarios asked the callers if they would be able to afford the apartment and who would be paying for the apartment.

\section{Survey}

Participants. A total of 41 landlords (19 females, 22 males) who had advertised for a one-bedroom apartment in one of the same three cities were interviewed. Telephone numbers were accessed using the same methods and sources as in the audit study. Originally, 97 landlords were called. Of these, 25 landlords were not interested in participating and 18 asked that the interviewer call them back at a more convenient time; these landlords were not called back. 13 of the numbers led to company recordings stating that the call would be recorded, and these calls were not completed.

Procedure. A random number generator was used to determine which phone numbers in the database were called 
for the survey. Upon making the call, the experimenter introduced herself, provided the title and purpose of the study, and its association with the University of Guelph. The participant was then assured of confidentiality and was told that their responses would in no way be connected with their personal or contact information. They were also informed of their freedom to withdraw at any time.

After the landlord agreed to participate in the survey, the experimenter began by asking for thoughts or words that the landlord associated with battered women and where they learned these associations. They were also asked if they felt they would be able to identify a battered woman, how they might do so, and if they would be willing to rent their unit to a woman with a history of domestic abuse. The fifth question asked if landlords could foresee any potential risks that may result from renting to a battered woman. If the landlord was able to think of at least one risk, the interviewer proceeded with a series of questions inquiring after the causes for and influences on the formation of these concerns, beginning with, "Why is this risk a concern for you?" If the landlord was unable to think of a risk, the survey was continued from Question 8, which asked, "How might you become more comfortable about renting a unit to a battered woman?" Overall, the survey consisted of 5 or 9 questions, depending on the landlord's response to Question 5. When the survey was complete, the interviewer requested that the the landlord not disclose the content of the call to any other individuals until May, 2010, and asked if the landlord had any questions about the survey or the study. After answering all questions honestly and respectfully, the interviewer concluded the phone call.

\section{RESULTS}

\section{Audit Study}

Analysis of the experimental data was conducted using the Statistical Package for the Social Sciences, version 17.0®. Observed and expected frequencies for apartment availability were compared in all cells of the 2 (White, Caribbean) x 3 (shelter, friend's house, control) design. When availability of the apartment was grouped only by living conditions, all expected cell frequencies exceeded five. To further break down the cells, the accent conditions were factored into the cross tabulation, which also produced expected frequencies greater than five in all cells. There were five instances in which landlords did not directly state the availability, but instead told the caller that they were waiting on a deposit for the unit from another potential tenant. Because this response was only found in the shelter condition, it was considered a deterring mechanism, and therefore included with the units that were unavailable (see Table 1).

A sequential logistic regression analysis was conducted, using availability of the rental unit as the outcome variable. A main effect of stated current living condition (shelter, friend's house, control) was found by entering this factor alone in the first model. This revealed that the stated living condition contributed significantly to the predictive power of the model, $\chi^{2}(2, N=180)=11.95, p=.003$ (see Figure 1 ). The main effect of accent was added to the model to investigate if there was a difference in availability between Canadian and Caribbean conditions, but this did not significantly improve predictability of the model, $\chi^{2}(1, N=$ $180)=0.16, p=.693$. Finally, an interaction between the stated living condition and the accent scenarios was added for the third model, but this also did not improve predictive power, $\chi^{2}(2, N=180)=3.91, p=.141$.

Variables were dummy coded in the first model in order to contrast the control condition and the shelter condition. This revealed a significant Wald Statistic, $\chi^{2}(2, N=180)=$ $8.70, p=.003$. The odds ratio showed that the control condition was 4.50 times more likely to produce availability of the apartment than the shelter condition. Dummy coding was then used on the first model to assess the univariate difference between availability in the friend's house condition and in the shelter condition, which also revealed a significant Wald Statistic, $\chi^{2}(1, N=180)=6.34, p=.012$. The friend's house condition was 3.25 times more likely to produce an available rental unit than the shelter condition. No significant difference in reported availability was found between the friend's house condition and control condition, $\chi^{2}(1, N=180)=.32, p=.571$.

The living condition variable was contrast coded to compare the availability in the shelter condition to the combined availability in the other two conditions (i.e., coded as shelter $=0$, friend's house $=1$, control $=1$ ) and a multinomial logistical regression was run on this variable. This was found to be significantly different from the constant only model, $\chi^{2}(1, N=180)=11.62, p=.001$, and revealed a significant Wald Statistic, $\chi^{2}(1, N=180)=11.37, p=.001$. The odds ratio revealed that the apartment was 3.79 times less likely to be available in the shelter condition than in the other two conditions combined.

\section{Survey}

NVivo $7{ }^{\circledR}$ was used to identify common responses in the surveys. All similar comments and responses that the participants provided for each question were grouped together and ordered from most to least common. The first

Table 1: Frequency of reported availability in current living and accent conditions.

\begin{tabular}{|c|c|c|c|c|}
\hline Accent & Living Condition & Available & $\begin{array}{l}\text { Not Available } \\
+ \text { Pending } \\
\text { Deposit (n) }\end{array}$ & Total \\
\hline \multirow[t]{3}{*}{ Canadian } & Control & 28 & $2+0=2$ & 30 \\
\hline & Friend's house & 27 & $3+0=3$ & 30 \\
\hline & Shelter & 17 & $8+5=13$ & 30 \\
\hline \multirow[t]{3}{*}{ Caribbean } & Control & 26 & $4+0=4$ & 30 \\
\hline & Friend's house & 25 & $5+0=5$ & 30 \\
\hline & Shelter & 23 & $7+0=7$ & 30 \\
\hline
\end{tabular}




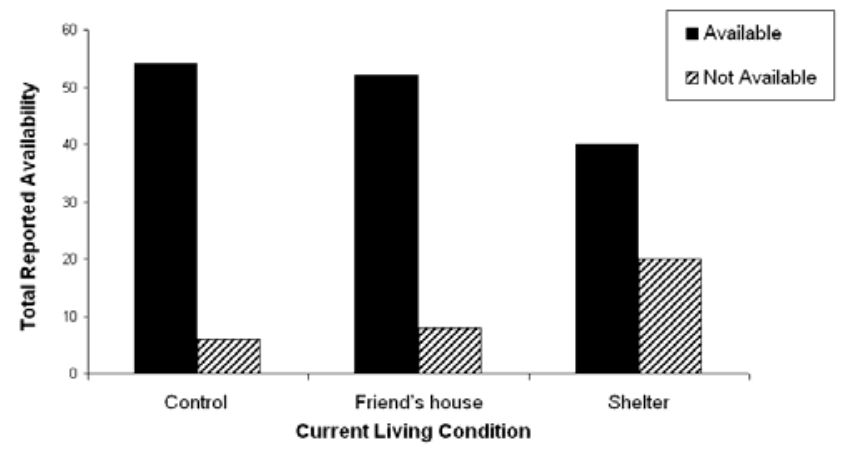

Figure 1: Frequency of reported availability for current living conditions.

question has been omitted from this report.

"Can you recall where you heard or learned your thoughts and ideas about battered women?" The most common source of general information about battered women was reported to be news programs and the newspaper (17). This was followed by dramatic television programs, police procedural dramas, and educational television programs (15). Movies were also a main source (11), though many of these participants admitted that it is often not a reliable source as events may be exaggerated. Word of mouth (i.e., stories told to participants by friends and family) was the fourth most common source (10). Twenty-nine percent of participants gained their knowledge about battered women through experiences in their immediate family (7) and their friends (5), while 7 percent had been in abusive relationships themselves (3). Five participants are currently renting to a battered woman or had done so in the past.

"Do you think you would be able to identify a potential tenant as a previously battered woman, even if she did not admit to it? " Twenty-two landlords (54\%) said that they would be able to identify a battered woman, while fourteen (34\%) said no, and seven (17\%) said they were not sure.

"How might you be able to identify a battered woman?" Besides the presence of bruises (8), landlords indicated that nervousness (10), jumpiness (4), and timidness, shyness, or quietness (7) would be the best indicators of whether a potential tenant was a battered woman. Participants said that a battered woman would avoid eye-contact (5) and be withdrawn (3). Of all landlords, four said that if a potential tenant was very concerned about security (4) and was eager to move in quickly (4), they would suspect that she may be a battered woman. Of the landlords who said they would not be able to identify a battered woman, four said that they would be unable to do so because indicting signs would be different for every individual. Two landlords said that even if bruises were present, they would not come to the conclusion that a woman was battered, because they avoid making that assumption; two said that it would be difficult because battered women are good at keeping things hidden, and two others said that they would not be able to identify a battered woman because they have had no experience in the area.

"If a battered woman was interested in renting the unit you have advertised, would you be willing to rent it to her? Why or why not?" Thirty-seven landlords (90\%) stated that they would be willing to rent to a battered woman. Of these landlords, thirteen explained that they would be willing to do so based on the desire to help the woman in her situation. Seventeen participants (37\%) stated that they would be willing to rent the unit to a battered woman as long as she passed the various checks which they normally run on their tenants (i.e., police record, credit checks, etc.) and if she or someone else was able to pay her rent. Nine landlords stated that they would be willing to rent the unit to a battered woman because they would not want to discriminate against her because of her situation, and that it was against the law to refuse to rent to anyone who is able to pay.

Four (10\%) said they would not rent a unit to a battered woman. Of these, two landlords were worried about their safety and that of their tenants, and one expressed concern regarding property damage in the event that the abuser would come to the building looking for the battered woman. Two of the landlords stated that they could not count on her to stay for the length of her lease because she may return to the abuser, while one said that he would not be comfortable because she could not be trusted to pay her rent.

"Do you foresee any potential risks that may result from renting to a battered woman? If so, what are they?"; "Why is this risk a concern for you?" Thirty-five landlords (85\%) reported that they could foresee potential risks that would result from renting to a battered woman. The most common concern was that the abuser would learn her current location and come to their building or house looking for her (30 participants, 73\%). The main reason that this was a concern was the risk of potential property damage (15). This was followed by concern for the other tenants' safety (14), the battered woman's safety (13), and that the intrusion of the abuser may disturb the tenants and lead to noise complaints (11). Additionally, landlords were worried about the inconvenience of having to contact the police (5). The harm to the landlord (5) and any children involved (5) were also listed concerns, as well as gaining a bad reputation as a result of the police coming to the building (3).

Landlords were also concerned about the financial stability of the battered woman (16), lest she be unable to pay the rent. More specifically, four participants said that if a battered woman had children, it would be an added financial risk because she would be more likely to care for them than to pay the rent, and two said that she is likely to be a financial risk because she is used to being dependant on her spouse and therefore, would not have an income.

The next most common concern was the risk that the battered woman would invite her spouse back to the apartment to reconcile (6). The main negative outcomes listed as a result of this was property damage (5) and 
disturbing the tenants (5). Two of these participants mentioned concern for the battered woman's safety.

Six participants listed the concern that the battered woman would be a substance user. This was based on concern for safety of other tenants and children in the house or building, in the event that she brought other substance abusers to her unit (3). The possibility that she would steal from the landlord in order to purchase drugs was also listed as a concern.

Seven of the landlords (17\%) stated that they could not foresee any specific risks occurring as a result of renting to a battered woman. Of these, two participants stated that they had no concerns because the police would be available to resolve any issues that arose.

"Where or how did you learn that this may be a problem for battered women?" Most commonly, landlords reported that their concerns were based on personal assumptions (13). Eleven landlords stated that they associated battered women with the listed risks because of things they had learned through movies, television, and the 'media'. Eight landlords stated that their concerns arose from experiences of having a battered woman as a past or current tenant, or from stories they had heard from other landlords. Six landlords reported that they associated these risks with battered women because they have a family history of woman abuse or they have friends who had experienced it. Four of the landlords reported associating these risks with battered women because of stories they had heard through word of mouth.

"How might you become more comfortable about renting a unit to a battered woman?" Eight landlords reported that they would be more comfortable with renting a unit to a battered woman if a restraining order against the abuser was in place. Some landlords (7) would feel more comfortable if they felt they could ensure her safety by increasing building security and having her emergency contacts in the event that she had an encounter with the abuser. Six landlords suggested that a co-signer on the lease would make them more comfortable. Five landlords would request information about the abuser, such as his history with the police, his violent tendencies, his appearance, and the likelihood that he will appear at the building. Five landlords stated that they would first like to ensure that she would not reconcile with the abuser and invite him to the unit or move back into his home. It was also noted that if she approached them about the apartment appearing confident (2), responsible (2), stable (3), and determined to change her situation (2), they would feel more comfortable renting an apartment to her. One landlord stated that he would feel more comfortable if there was government support involved to help him.

Four landlords said that they are already comfortable with renting to a battered woman, while eight stated that there is nothing that could make them more comfortable because every situation is unpredictable, and nothing can ensure that the abuser will not appear at the building.

\section{Questions and Comments}

Most commonly, landlords stated that the survey brought to their attention an issue they have not yet thought of (5). Otherwise, every comment was unique. At the closing of one interview, a participant discussed the stigma associated with battered women which leads people to believe that these women are drug users and are of "lower class". She explained that this stigma is perpetuated by news-media, but that many survivors of domestic violence are middle-class mothers with jobs who keep the violence well hidden, and there is no reason to associate these women with drug use or financial instability. In another interview, it was mentioned that battered women are likely to be of low socio-economic status and that middle-class women are not likely to be trapped in such a situation. This assumption is what led this participant to make an association between battered women and drug use. Another landlord made multiple comments throughout the interview regarding his ability to use violence and abuse against the battered woman to ensure that she would not make any trouble, which he delivered in a humourous manner. Another participant speculated that although landlords may want to help a woman in this situation, their first concern will always be the rent; concern about rent being paid will outweigh any sympathy.

The most common question asked was to repeat the purpose of the survey (5). Ten participants requested contact information so they could follow up on the research.

\section{Discussion}

The results of this study support past research and the primary hypothesis. Landlords were less likely to state that an apartment is available to a woman who is currently living in a shelter than a woman who was staying at a friend's house or a woman who did not state her current living situation. Because most landlords agreed to show the apartment to callers who were living at a friend's house, we can infer that the landlords were responding specifically to the fact that the caller was a battered woman, and not because they were worried about general instability. There was also no difference between the control and friend's house conditions, indicating that simply stating living condition did not affect the landlord's response. Contrary to predictions, having a Caribbean accent and living in a shelter did not result in fewer available apartments than having a Canadian accent in the same current living condition. In fact, it appears that Canadian confederates living in a shelter were told that the apartment was available less often than their Caribbean counterparts. This may be because landlords feel they must abide by anti-racism laws, yet feel it is their right to reject a battered woman as a tenant. Anti-racism laws in Canada are relatively well-acknowledged, whereas no such 
laws have been established specifically to protect battered women. Thus, when identifying a caller as 'foreign', landlords may suppress any illegal discriminatory behaviour to a degree that they would not for an abused woman. Although there was no significant difference in reported availability between Caribbean callers and Canadian callers in the shelter condition, landlords were noted to have asked the confederates in the accent-shelter condition if they would be able to pay the rent, how they would afford living in the apartment, and who would pay their rent for them. On the other hand, the Canadian accent confederates were never questioned about their ability to pay the rent in any of the current living conditions. Thus, it is possible that landlords were honest about availability because of their awareness of anti-racism laws, but may have tried to deter using other methods. This is also supported by research which shows that people frequently make an implicit association between Black individuals and low socio-economic status $[17,18]$. It is also possible that because the dialogue was so brief the landlords did not have enough time to detect the Caribbean accent.

The survey helped explain the cause of discrepancy in availability between the shelter condition and the control and friend conditions in the audit study. Many landlords believed that the qualities attributed to battered women would be fairly obvious, and that these women would be nervous and socially uncomfortable. It appears that landlords had a somewhat stereotypical representation of a battered woman expecting her to be weak and helpless. This is in line with the qualities attributed to battered women due to the Battered Woman Syndrome, a psychological theory used in the legal system, which predicts a learned helplessness in women who experience domestic abuse [19].

More landlords stated that they would be willing to rent to a battered woman than has been recorded in past research [8]. This may be associated with the relatively small size of the cities involved in the study. Research has shown that helpful behaviour is less present in large cities than in small or medium cities [20], which could be used to explain why the landlords in the present study reported being willing to rent to a battered woman more often than those in past studies [8, 11]. However, the high rate of reported willingness in the survey is not reflected in the reported availability in the audit study. Although a high majority of landlords answered that they would rent to a battered woman, the audit study revealed that women with a history of abuse are significantly more likely to be told an apartment is unavailable. Thus, it is also possible that the rate of reported willingness to rent was high because most landlords were merely providing a socially desirable response. As an alternative explanation, one can consider the history of the individual participants in the survey. As noted above, twenty-nine percent of the participants had either experienced domestic abuse, had a family history of abuse, or had friends who survived domestic abuse. Thus, another possibility for the discrepancy between the reported willingness in the survey and the reported availability in the audit study is that the landlords who agreed to participate in the survey are more interested or emotionally invested in the issue than the average landlord; on the other hand, those who had less interest in the issue - and therefore potentially less sympathy for battered women - did not participate. Additionally, all landlords who had direct or indirect experience with woman abuse reported that they would be willing to rent to a battered woman. Only nine of the participants acknowledged that to refuse the unit to a battered woman would be to discriminate against her. The fact that such a low number of participants acknowledged this reflects a severe lack of awareness of the issue.

Most landlords said that they could foresee problems that would result from renting to a battered woman. The fourth most common outcome that landlords were concerned about was the battered woman's safety. Because abuse is much less likely to occur if a battered woman were to live in this advertized apartment than if she were to stay with the abuser, it is possible that landlords are more concerned about having to witness continued abuse than being worried about the actual occurrence of it.

When asked how they made the association between battered women and the risks that they listed, most participants reported that their concerns were the result of basic assumptions. It is possible that the underlying source of these assumptions is the media, based on responses to the second question of the survey, wherein landlords revealed that the main source of general information was the news, moves, and television. This theory is supported by Berns and Schweingruber, who interviewed 'non-victim' participants about how they understand domestic violence and on what sources their opinions are based. These researchers found that non-victims have a very limited range of sources of information, and thus describe victims as being passive, weak, and having low self-esteem. Furthermore, it was found that they were more likely to base these simple representations of battered women on information gathered from the media (i.e., television and news-media) and on 'common knowledge'. These researchers also concluded that basic assumptions are based on the media [21].

Landlords were asked what could be done to make them more comfortable with renting to a battered woman to help identify ways to increase her likelihood of being accepted as a tenant. Most landlords responded to this question with attainable requests, which women in this situation could carry out in most cases. Of the landlords who stated that nothing could be done to make them more comfortable, only one said that they would not be willing to rent to a battered woman. The remainder stated that although nothing could be done to prevent any potential negative occurrences while renting to a battered woman, they were willing to take the risk to help her. Two out of three of these landlords were those who had directly experienced domestic abuse, which 
can be explained by the probability that most past survivors of abuse have a more realistic understanding of the issue [21]. The most common type of request was related to the woman's behaviour. Landlords often stated that they would feel comforted if the battered woman approaching them seemed determined to change her situation and eager to start new and take control of her life. The responses provided for this question can be used by shelter employees and transitional housing programs to help prepare women for housing-seeking. If women preparing to leave the shelter are aware of what they can provide and how they can behave to make landlords more comfortable, they will gain an advantage when looking for a long-term home.

The opportunity for landlords to provide additional thoughts or concerns at the conclusion of the interview showcased the wide range of perspectives on the issue. The statement made that concern for rent being paid will outweigh any sympathy for a woman fleeing from domestic violence is a harsh observation, but it appears to represent the general attitude that the surveyed landlords had on the topic. Efforts should be made to eliminate the general notion that battered women are helpless and unreliable. To do this, negative representations of battered women as financially unstable and wholly dependent on their spouse should be publically countered. Furthermore, programs should be implemented to educate landlords on the repercussions of rejecting battered women as tenants, including the increase of the likelihood that she will eventually become homeless or return to her abuser [6].

In regards to future research on the discrimination against ethnic-identified battered women, analyses should be done on the exact dialogue between the woman and the potential landlord, as landlords in this study were shown to reveal reluctance in their speech and behaviour. Coding for deterring phrases could reveal more about discrimination than simply recording the stated availability. Lengthening the dialogue between the confederate and the landlord may be useful as it will provide landlords with the opportunity to detect an accent, while they may have been unable to do so during the brief dialogue of the present study. Future research should also further investigate ways to make landlords more comfortable with renting to a battered woman to adequately prepare these women when they begin searching for long-term homes. Methods should also be developed to effectively educate landlords on the issue and the major impact they have when they choose to reject or accept a battered woman as a tenant.

\section{REFERENCES}

1. Public Health Agency of Canada (2008). Women abuse. Public Health Agency of Canada [Online]. Available: www.phac-aspc.gc.ca/ncfv-cnivf/publications/femviofeng.php.
2. Zorza, J. (1991). Women battering: A major cause of homelessness. Clearinghouse Review, 25, 421.

3. Sev'er, A. (2002). Fleeing the house of horrors: Women who have left abusive partners. Toronto, ON: University of Toronto Press.

4. Sev'er, A. (1997). Recent or imminent separation and intimate violence against women: A conceptual overview and some canadian examples. Violence Against Women: An International and Interdisciplinary Journal, 3(6), 566-589.

5. Bassuk, E.L., \& Rosenburg, L. (1988). Why does homelessness occur? A case-control study. American Journal of Public Health, 78(7), 783-788.

6. Metraux, S. \& Culhane, D. (1999). Family dynamics, housing, and recurring homelessness among women in New York City homeless shelters. Journal of Family Issues, 20, 371-396.

7. Baker, C.K., Cook, S.L., \& Norris, F.H. (2003). Domestic violence and housing problems: A contextual analysis of women's help-seeking, received informal support, and formal system response. Violence Against Women, 9(7), 754-783.

8. Barata, P.C., \& Stewart, D.E. (2010). Searching for housing as a battered woman: Does discrimination affect reported availability of a rental unit? Psychology of Women Quarterly, 34, 43-55.

9. Dion, K. L. (2001). Immigrant's perceptions of housing discrimination in Toronto: The housing of new Canadians project. Journal of Social Issues, 57, 523-539.

10. Yinger (1986). Measuring racial discrimination with fair housing audits: Caught in the act. The American Economic Review, 76(5), 881-893.

11. CERA (2009). “Sorry, it's rented.”: Measuring discrimination in toronto's rental housing market. CERA [Online]. Available: www.equalityrights.org/cera/docs/CERAFinalReport.pdf

12. Bureau of Justice Statistics (2007). Intimate partner violence in the u.s.: Victim characteristics. Bureau of Justice Statistics [Online]. Available: www.ojp.usdoj.gov/bjs/intimate/victims.htm\#race

13. Jasper, M.C. (2007). The law of violence against women $\left(2^{\text {nd }}\right.$ ed.). New York: Oceana.

14. Lockhart, L., \& White, B. (1989). Understanding marital violence in the Black community. Journal of Interpersonal Violence, 4, 421-436.

15. West, T. C. (1999). Wounds of the spirit: Black women, violence and resistance ethics. New York: New York University Press.

16. Donnelly, D.A., Cook, K.J., Van Ausdale, D., \& Foley, L. (2005). White privilege, color blindness, and services to battered women. Violence Against Women, 11(1), 637.

17. Amadio, D.M., \& Devine, P.D. (2006). Stereotyping and evaluation in implicit race bias: Evidence for 
independent constructs and unique effects on behaviour. Journal of Personality and Social Psychology, 91(4), 652-661.

18. Devine, P. G., \& Elliot, A. J. (1995). Are racial stereotypes really fading? The princeton trilogy revisited. Personality and Social Psychology Bulletin, 21, 1139-1150.

19. Walker, L. E. (2000). The battered woman syndrome. (2nd ed.) New York: Springer Publishing Company, Inc.
20. Amato, P.R., \& Cook, J. (1983). The helpfulness of urbanites and small town dwellers: A test between two broad theoretical positions. Australian Journal of Psychology, 35(2), 233-243.

21. Berns, N. \& Schweingruber, D. (2007). "When you're involved, it's just different”: Making sense of domestic violence. Violence Against Women, 13(3), 240-261. 